\title{
The Role of Vitamın D in Implant Success
}

\author{
Aleyna Karaoglu¹, Zeynep Seda Pekcetin'2, Ege Koray ${ }^{3}$, Huseyin Yalcin Soyer ${ }^{4}$, Meltem Koray5* \\ ${ }^{1}$ Faculty of Dentistry, Istanbul University, Istanbul, Turkey \\ ${ }^{2}$ Department of Oral and Maxillofacial Surgery, Faculty of Dentistry, Biruni University, Istanbul, Turkey \\ ${ }^{3}$ Faculty of Medicine, Medeniyet University, Istanbul, Turkey \\ ${ }^{4}$ Private Practice, Bursa, Turkey \\ ${ }^{5}$ Department of Oral and Maxillofacial Surgery, Faculty of Dentistry, Istanbul University, Istanbul, Turkey \\ Email: *mkoray@istanbul.edu.tr
}

How to cite this paper: Karaoglu, A., Pekcetin, Z.S., Koray, E., Soyer, H.Y. and Koray, M. (2019) The Role of Vitamın D in Implant Success. Open Journal of Stomatology, 9, 260-269.

https://doi.org/10.4236/ojst.2019.911027

Received: October 17, 2019

Accepted: November 11, 2019

Published: November 14, 2019

Copyright $\odot 2019$ by author(s) and Scientific Research Publishing Inc. This work is licensed under the Creative Commons Attribution International License (CC BY 4.0).

http://creativecommons.org/licenses/by/4.0/

\begin{abstract}
Vitamin $\mathrm{D}$ is a multifunctional hormone that is mostly produced in the skin following exposure to ultraviolet B sunlight. It coordinates the physiological functions by controlling calcium and phosphate metabolism, promotes growth, and induces necessary remodeling of the bones and teeth. As known high serum vitamin D levels have beneficial effects on oral health and that exposure to safe sunlight can reduce the risk of periodontal disease and thus affect implant success. In order to prove this hypothesis, we conducted a detailed literature review. In the literature review, 3 clinical studies and 2 case reports of implant and vitamin D were found. Although vitamin D is highly correlated with bone metabolism, and expected a very close relationship with implant success, a large number of experimental studies and few clinical studies unfortunately showed contradictory results and no direct studies showing vitamin D and implant success were found. Therefore, it is necessary to demonstrate the existence or absence of this relationship by conducting much broader studies.
\end{abstract}

\section{Keywords}

Vitamin D, Implant Success, Osseointegration

\section{Introduction}

Vitamin D is a multifunctional hormone that is mostly produced in the skin following exposure to ultraviolet (UV) B sunlight. A negligible amount comes from exogenous sources (foods and supplements). It coordinates the physiological functions by controlling calcium and phosphate metabolism, promotes growth, and induces necessary remodeling of the bones and teeth [1]. The important role of 
vitamin $\mathrm{D}$ in the regulation of musculoskeletal health by maintaining mineral ion homeostasis is elaborated elsewhere [1] [2].

To assess the vitamin D level in the individual, the $25(\mathrm{OH}) \mathrm{D}$ level with a half-life of 2 - 3 weeks, indicating both vitamin D intake and endogenous production, should be considered. Many studies have been conducted to identify deficiency of vitamin D and to determine the normal range of $25(\mathrm{OH}) \mathrm{D}$ level. In the light of these studies; Vitamin D deficiency if $25(\mathrm{OH}) \mathrm{D}$ is less than 20 $\mathrm{ng} / \mathrm{mL}$, vitamin D insufficiency between 21 and $29 \mathrm{ng} / \mathrm{mL}$, sufficient level if preferred is greater than $30 \mathrm{ng} / \mathrm{mL}$ (preferred range is $40-60 \mathrm{ng} / \mathrm{mL}$ ) and higher than $150 \mathrm{ng} / \mathrm{mL}$ [3] [4].

Vitamin D, on the other hand, stimulates osteoclast differentiation and activity, resulting in increased bone resorption. Furthermore, parathyroid hormone (PTH), and vitamin D can induce skeletal fibroblast growth factor 23 (FGF23) production to regulate serum phosphate levels and can thereby influence bone resorption. FGF23, a member of the FGF19 subfamily of fibroblast growth factors, has been shown to play a key role in balancing mineral ion homeostasis [2] [5]. The effect of vitamin D and calcium supplements in the treatment of Bone Mineral Density (BMD) reduction depends on the regulation of calcium and phosphorus concentration in the blood [6].

Directly or indirectly, the $1,25(\mathrm{OH})_{2} \mathrm{D}_{3}$ /Vitamin D Receptor (VDR) pathway may influence bone remodeling by mediating differentiation and maturation of osteoblasts and osteoclasts. $1,25(\mathrm{OH})_{2} \mathrm{D}_{3} / \mathrm{VDR}$ pathways in osteoblasts; type I enhances expression of osteogenic genes such as those encoding collagen, alkaline phosphatase, osteocalcin and osteopontin, and accelerates bone formation. In addition, VDR polymorphism has been shown to be associated with an increased risk of chronic periodontitis and other inflammatory conditions in the presence of exogenous etiological factors [7].

\section{The Importance of Vitamin D in Jaws}

Mandibular bone is one of the four tissues that make up the periodontium. It is therefore closely associated with osteoporosis and periodontal disease. Low levels of vitamin $\mathrm{D}$ and calcium lead to a negative calcium balance, disruption of bone mineralization, and loss of bone structure. Vitamin D deficiency causes rashitzm in children and osteoporosis in adults and increased risk of bone fracture [6]. Alshouibi et al. in a study conducted on 562 patients, they found that total vitamin $\mathrm{D}$ intake was associated with improved periodontal health compared to measurements of alveolar bone loss, pocket depth and attachment loss [8].

Syed et al. recommended that patients at risk for vitamin D deficiency should be screened before performing mandible operations and should receive vitamin D supplementation from insufficient serum levels before surgery [9].

Krall et al. found that vitamin D and calcium supplementation significantly reduced tooth loss in the elderly [10]. Andresen et al. observed that there is a significant relationship between calcium and vitamin $\mathrm{D}$ taken as a supplement. 
Also periodontal health, additional vitamin $\mathrm{D}$ and calcium taken can improve peridontal health, increase bone mineral density in mandible and decrease alveolar bone resorption [11].

Systemic increase in cytokines affecting bone resorption in the entire skeletal and jawbone can be seen in people with low BMD. This information shows that vitamin D may be useful in the treatment of peridontitis not only with its effect on bone but also with its anti-inflammatory effect [6].

It is known that there is a correlation between bone loss and intraoral bone and tooth loss, and calcium, vitamin D supplementation and intraoral bone modulation are affected and dental retention is increased to prevent this [10].

To summarize, as known high serum vitamin D levels have beneficial effects on oral health and that exposure to safe sunlight can reduce the risk of periodontal disease and thus affect implant success. In order to prove this hypothesis, we conducted a detailed literature review.

\section{Implant and Vitamin D}

Vitamin D deficiency is a risk factor affecting the jaw bones [8]. In a study, the criteria such as periodontal pocket depth, bone level and attachment loss were examined in patients receiving daily vitamin $\mathrm{D}$, and the progression of periodontal diseases was decreased in patients receiving high vitamin D. Calcium intake leads to a similar effect; periodontal, ginjivitis disease decreases with antiinflammatory effect, the success of periodontal surgery increases, decrease of bleeding [10] [12] [13]. There was an association between periodontal health status, BMD and implant success [14].

Uwitonze et al. (2018) reported that, inadequate vitamin D status can compromise osseous healing in the oral cavity and beyond [1]. Sufficient osseous healing is main factor for osseointegration hence implant success. Long-term stable implants are the primary target of dental implantology and implant survival and hence osseointegration are known to be dependent on a number of factors. Current research describing the mechanism of implant failure includes tobacco use, diabetes, bone preparation, and local bone necrosis due to heat generation during implant placement. Failures, especially due to lack of osseointegration, are serious problems and may be related to the patient's systemic health status. Recognition of systemic risk factors has shown that failure rates can be reduced and predictability can be increased [15] [16].

Since osseointegration of dental implants also depends on bone metabolism, there is a possibility that low levels of vitamin D in the blood may adversely affect healing processes and new bone formation on the implant surface [16]. Current case reports have raised the question of the effect of vitamin D deficiency on the survival of the implant during early stage recovery [15].

As known, good bone metabolism is indispensable for successful in bone regeneration procedures in osseointegration of implants [17].

Vitamin D is known to increase osteocalcin, osteopontin, calbindin and 24 hydroxylase levels in bone metabolism, increase extracellular matrix protein for- 
mation made by osteoblasts and provide osteoclast activity [18]. Vitamin D behind bone formation supports osseoimmunology, which contributes to early healing of implants. However, the fact that vitamin D monitoring could not be performed routinely in implantology is a deficiency for the evidence to be presented. Again, the relationship between vitamin D deficiency and early loss of implants has not been clearly established [19] [20] [21].

\section{Experimental Research on Implant and Vitamin D}

In an experimental study, Satué et al. evaluated the biological effect of titanium implants coated with UV-activated 7-dehydrocholesterol (7-DHC), the precursor of vitamin D3, on cytotoxicity and osteoblast differentiation. According to these results, 7-DHC coated titanium implants had positive effects on osteoblast proliferation and differentiation compared to control implants (implants without 7-DHC coating) [22]. Interestingly, the results of Naito et al. showed no significant difference in new bone formation around implants with and without vitamin D3 coatings. As an explanation in this context, both vitamin D coated and uncoated implants have been shown to have rough surfaces [23]. However, it is still unclear whether vitamin D-coated dental implants have osseointegration effect in vivo, and it is concluded that the effect of vitamin D supplementation on osseointegration of implants is still controversial and requires further investigation [23].

Dvorak et al., fifty ovariectomized rats; they were divided into three groups, which were fed 8 days of vitamin D-free diet, 6 weeks of vitamin D-free diet, and then switched to a standard diet containing $2400 \mathrm{IU} / \mathrm{kg}$ of vitamin D, and the control group received only a standard diet. Implant placement showed that vitamin $\mathrm{D}$ deficiency had a negative effect on cortical peri-implant bone formation in ovariectomized rats and this could be compensated by vitamin $\mathrm{D}$ supplementation. This study is of particular importance in that it provides the first point of view of the potential effect of vitamin D supplementation on implant dentistry [24].

Salomo et al. they removed the distal roots of the premolar of six dogs, 12 of them before the implant placement of a $10 \%$ solution of vitamin $\mathrm{D}$ dipped in a total of 24 immediate titanium implants were placed. Within the limits of this study, although less crestal bone loss and 10\% greater bone implant contact were seen in the group treated with vitamin D during the 12-week follow-up period; they reported that topical administration of vitamin $\mathrm{D}$ have not seen a greater effect on osseointegration of dental implants [25].

Cho et al. in their study, they applied vitamin D coated implants to the tibia of rabbits; the osseointegration level was determined at 4 and 12 weeks. According to their results of the study, it was observed that the coating with $1,25(\mathrm{OH})_{2} \mathrm{D}_{3}$ / PLGA solution formed submicron-sized particles capable of stimulating bone formation adjacent to the surface of implants placed in bone [26].

Zhou et al. aimed to investigate the effect of $1,25(\mathrm{OH})_{2} \mathrm{D}_{3}$ on implant osseointegration in osteoporotic mice. All animals were randomly divided into two groups: control group (10 mice) and experimental group (10 mice) treated with 1,25 
$(\mathrm{OH})_{2} \mathrm{D}_{3}$. After 8 weeks, histological and biomechanical analysis of the implants revealed that the trabecular bone density and the trabecular connective density were increased and the mean trabecular bone density and percentage of bone volume and osseointegration were increased in the $1,25(\mathrm{OH})_{2} \mathrm{D}_{3}$ group compared to the control group. As a result, implant stability improved with vitamin $\mathrm{D}$ supplemented implants. Increased implant stabilization; have concluded that peri-implant bone density is related to implant osseointegration and peri-implant trabecular structure [27].

Wu et al. investigated the effect of insulin and vitamin D treatment on implant osseointegration in diabetic rats. After 12 weeks of follow-up, blood glucose levels, body weight and serum $1,25(\mathrm{OH})_{2} \mathrm{D}_{3}$ levels were found to be low and less implant osseointegration was detected compared to the control group. It was observed that insulin treatment had a positive effect on body weight and serum $1,25(\mathrm{OH})_{2} \mathrm{D}_{3}$ levels in diabetic rats and combined therapy normalized hyperglycemia in diabetic rats and increased bone volume ratio and bone integration percentage. These results suggest that combined treatment of insulin and vitamin D may be an effective approach to increase implant stabilization in diabetic rats, but further investigations are needed to determine whether the results should be included in human studies [28].

Vitamin D deficiency is a common condition in chronic kidney disease (CKD) which adversely affects bone regeneration and fracture healing. In a study by Liu et al., It was aimed to investigate the effect of vitamin D supplementation on implant osseointegration in CKD mice. Uremia was induced by nephrectomy in mice; The animals received $1,25(\mathrm{OH})_{2} \mathrm{D}_{3}$ intraperitoneally three times a week for four weeks, and titanium implants were placed into the femur two weeks later. Serum measurements confirmed that $1,25(\mathrm{OH})_{2} \mathrm{D}_{3}$ levels decreased in CKD mice, which was successfully corrected with vitamin D injections. Histomorphometric analyzes showed that the bone implant contact ratio and bone volume around the implant increased significantly in the vitamin D supplementation group [29].

As a result, in order to investigate the relationship between implant osseointegration and vitamin $\mathrm{D}$, implants were applied in animals such as dogs, rats, rabbits and mice carrying diseases associated with vitamin D metabolism such as chronic kidney disease, osteoporosis, diabetes, and the rate of bone and implant contact with vitamin D supplementation and bone stability was observed. Animal experiments have also been performed on topical application of vitamin D, and bone formation is stimulated in cases where implant surfaces are covered with vitamin $\mathrm{D}$, and crestal bone loss is reported to be less. With the positive effects observed in animal experiments in general, it is revealed that further studies are needed for the effect of vitamin D on humans.

\section{Clinical Research on Implant and Vitamin D}

In the literature review, 3 clinical studies and 2 case reports of implant and vitamin D were found [15] [16] [18] [30] [31]. 
In the study of Mangano et al. between 2013 and 2015, the effect of patientdependent variables on implant survival was calculated. 822 patients treated with 1625 implants were selected for this study; a total of 27 early failures (3.2\%) were recorded; statistical analysis, $9(2.2 \%)$ in patients with serum vitamin $\mathrm{D}>30$ $\mathrm{ng} / \mathrm{mL}$ levels, 16 (3.9\%) in patients with levels between 10 and $30 \mathrm{ng} / \mathrm{mL}$ and 2 ( $9 \%$, in patients with levels $<10 \mathrm{ng} / \mathrm{mL}$ ). The incidence of premature failure almost doubled in patients with inadequate serum vitamin D levels (10 - 30 $\mathrm{ng} / \mathrm{mL}$ ) and was even higher in patients with severe vitamin D deficiency (9.0\%). According to the statistical analysis, the incidence of failure in patients with severe vitamin $\mathrm{D}$ deficiency increased, but as a result, there was no statistically significant difference in the incidence of early implant failure in these three patient groups. This study failed to provide an effective link between low vitamin D levels and the risk of early implant failure. According to Mangano et al., further studies are needed to investigate this issue [30].

In addition, Mangano et al. included 885 patients (1740 implants) who underwent dental implantation to investigate whether there was a relationship between low serum vitamin D levels and early implant failure. All patients who underwent regenerative bone surgery procedures before implant placement, and patients with systemic pathologies or chemotherapy were excluded from this study. Out of a total of 885 patients, 35 early implant failure (3.9\%) were reported. There was no correlation between early implant failure and gender, age, smoking habit or history of periodontal disease. 3 early implant failure (11.1\%) of 27 patients with serum vitamin D levels $<10 \mathrm{ng} / \mathrm{mL}, 20$ early implant failure (44\%) of 448 patients between 10 and $30 \mathrm{ng} / \mathrm{mL}, 12$ early implant failure (410\%) of $>30$ $\mathrm{ng} / \mathrm{mL}$ 2.9) reported. Although there was an increased risk of early implant failure with decreased serum vitamin D levels, no statistically significant difference was reported between these three groups [16].

Two patients with vitamin D deficiency and early implant failure in Fretwurst et al. reported. Any case had no systemic disease, regular medication use, alcohol or nicotine use. Both patients lost their teeth a few years before implant placement, and the first patient (48 years old) underwent a crestal bone graft with autologous material prior to implant placement. 3 months after the graft procedure, 2 implants were applied to the 36 and 37 regions, and the bone graft was completely revascularized and confluent. One day after the operation, the patient was reported to have pain. After 3 days the pain increased and both implants were removed. While the implants were removed, large osteolysis areas surrounding them and debris of the region were seen and wound closure was completed. The second implant surgery was performed 6 months later by placing 2 implants in 36 and 37 regions, and the mandible was well vascularized and no granulation tissue was seen in the resettlement. After 3 days, the two implants had to be removed because of severe pain that persisted without any signs of soft tissue swelling, swelling or abscess. At this point, relevant parameters of bone metabolism were screened and diagnosed as vitamin D deficiency (vitamin D serum level $11 \mathrm{ng} / \mathrm{ml}$ ). After the vitamin D supplementation and six-month re- 
covery period, a third surgical intervention was planned, with an implant placed in the 36 region at a serum D level of $46 \mathrm{ng} / \mathrm{ml}$. It was observed that the old area completely re-ossified during implant placement. Second stage surgery was successfully completed and prosthetic restoration started [15].

In 2014, Bryce and Macbeth published a 29-year-old patient with an immediate implant. Five months after the operation, no osseointegration of the implant was found. Tests showed that the patient had severe vitamin D deficiency, which may have been a factor in implant failure. The patient was then supplemented with vitamin D until normal levels were reached [18].

In a randomized, double-blind, controlled study in 2016, Schulze-Späte et al. investigated the effects of vitamin D and calcium combination and supplementation on new bone formation following maxillary sinus elevation. Ten patients were included in the test group and given vitamin $\mathrm{D}$ and calcium; the other 10 patients were assigned to the control group and received only calcium. Six to eight months after surgery for bone regeneration, when bone samples were taken for histological analysis during implant placement, although vitamin D supplementation increased serum vitamin D levels with potentially positive effects on bone remodeling at the cell level, no statistically significant difference was found between the two groups [31].

\section{Conclusion}

Growing awareness by dental health care providers for keeping the optimal vitamin D status is necessary for maintaining disease-free oral health is of the vital importance [1]. Although vitamin D is highly correlated with bone metabolism, and expected a very close relationship with implant success, a large number of experimental studies and few clinical studies unfortunately showed contradictory results and no direct studies showing vitamin $\mathrm{D}$ and implant success were found [15] [16] [18] [30] [31]. This is probably due to the fact that two of the five published clinical trials on implant and vitamin D were case reports, two were retrospective studies and one was related to sinus augmentation. Therefore, it is necessary to demonstrate the existence or absence of this relationship by conducting much broader studies. That kind of prospective studies should design as long-term and case-control.

\section{Conflicts of Interest}

The authors declare no conflicts of interest regarding the publication of this paper.

\section{References}

[1] Uwitonze, A.M., Murererehe, J., Ineza, M.C., Harelimana, E.I., Nsabimana, U., Uwambaye, P. and Razzaque, M.S. (2018) Effects of Vitamin D Status on Oral Health. The Journal of Steroid Biochemistry and Molecular Biology, 175, 190-194. https://doi.org/10.1016/j.jsbmb.2017.01.020

[2] Razzaque, M.S. (2014) Bone-Kidney Axis in Systemic Phosphate Turnover. Arc- 
hives of Biochemistry and Biophysics, 561, 154-158.

https://doi.org/10.1016/j.abb.2014.06.031

[3] Matthias, W. and Michael, H. (2013) Vitamin D-Effects on Skeletal and Extraskeletal Health and the Need for Supplementation. Nutrients, 5, 111-148.

https://doi.org/10.3390/nu5010111

[4] Holick, M.F., Binkley, N.C., Bischoff-Ferrari, H.A., Gordon, C.M., Hanley, D.A., Heaney, R.P. and Weaver, C.M. (2011) Evaluation, Treatment, and Prevention of Vitamin D Deficiency: An Endocrine Society Clinical Practice Guideline. The Journal of Clinical Endocrinology \& Metabolism, 96, 1911-1930.

https://doi.org/10.1210/jc.2011-0385

[5] Yuan, Q., Sitara, D., Sato, T., Densmore, M., Saito, H., Schüler, C., Lanske, B., et al. (2011) PTH Ablation Ameliorates the Anomalies of Fgf23-Deficient Mice by Suppressing the Elevated Vitamin D and Calcium Levels. Endocrinology, 152, 4053-4061. https://doi.org/10.1210/en.2011-1113

[6] Jagelavičienè, E., Vaitkevičienè, I., Šilingaitè, D., Šinkūnaitė, E. and Daugèlaitė, G. (2018) The Relationship between Vitamin D and Periodontal Pathology. Medicina, 54, 45. https://doi.org/10.3390/medicina54030045

[7] Khammissa, R.A.G., Ballyram, R., Jadwat, Y., Fourie, J., Lemmer, J. and Feller, L. (2018) Vitamin D Deficiency as It Relates to Oral Immunity and Chronic Periodontitis. International Journal of Dentistry, 2018, Article ID: 7315797. https://doi.org/10.1155/2018/7315797

[8] Alshouibi, E.N., Kaye, E.K., Cabral, H.J., Leone, C.W. and Garcia, R.I. (2013) Vitamin D and Periodontal Health in Older Men. Journal of Dental Research, 92, 689-693. https://doi.org/10.1177/0022034513495239

[9] Syed, N., Chiu, G.A. and Korczak, P. (2017) Should Patients Take Vitamin D before Mandibular Operations? British Journal of Oral and Maxillofacial Surgery, 55, 841843. https://doi.org/10.1016/j.bjoms.2017.07.004

[10] Krall, E.A., Wehler, C., Garcia, R.I., Harris, S.S. and Dawson-Hughes, B. (2001) Calcium and Vitamin D Supplements Reduce Tooth Loss in the Elderly. The American Journal of Medicine, 111, 452-456. https://doi.org/10.1016/S0002-9343(01)00899-3

[11] Andresen, C., Olson, E., Nduaka, C.I., Pero, R. and Bagi, C.M. (2006) Action of Calciotropic Hormones on Bone Metabolism-Role of Vitamin D3 in Bone Remodeling Events. American Journal of Immunology, 2, 40-51. https://doi.org/10.3844/ajisp.2006.40.51

[12] Dietrich, T., Nunn, M., Dawson-Hughes, B. and Bischoff-Ferrari, H.A. (2005) Association between Serum Concentrations of 25-Hydroxyvitamin D and Gingival Inflammation. The American Journal of Clinical Nutrition, 82, 575-580. https://doi.org/10.1093/ajcn/82.3.575

[13] Heaney, R.P. (2014) Guidelines for Optimizing Design and Analysis of Clinical Studies of Nutrient Effects. Nutrition Reviews, 72, 48-54. https://doi.org/10.1111/nure.12090

[14] Bashutski, J.D, Eber, R.M., Kinney, J.S., Benavides, E., Maitra, S., Braun, T.M., Giannobile, W.V. and McCauley, L.K. (2010) Teriparatide and Osseous Regeneration in the Oral Cavity. The New England Journal of Medicine, 363, 2396-2405. https://doi.org/10.1056/NEJMoa1005361

[15] Fretwurst, T., Grunert, S., Woelber, J.P., Nelson, K. and Semper-Hogg, W. (2016) Vitamin D Deficiency in Early Implant Failure: Two Case Reports. International Journal of Implant Dentistry, 2, 24. https://doi.org/10.1186/s40729-016-0056-0

[16] Mangano, F.G., Oskouei, S.G., Paz, A., Mangano, N. and Mangano, C. (2018) Low 
Serum Vitamin D and Early 20 Dental Implant Failure: Is There a Connection? A Retrospective Clinical Study on 1740 Implants Placed in 885 Patients. Journal of Dental Research, Dental Clinics, Dental Prospects, 12, 176-182. https://doi.org/10.15171/joddd.2018.027

[17] Faine, M.P. (1995) Dietary Factors Related to Preservation of Oral and Skeletal Bone Mass in Women. Journal of Prosthetic Dentistry, 73, 65-72. https://doi.org/10.1016/S0022-3913(05)80275-6

[18] Bryce, G. and MacBeth, N. (2014) Vitamin D Deficiency as a Suspected Causative Factor in the Failure of an Immediately Placed Dental Implant: A Case Report. Journal of the Royal Naval Medical Service, 100, 328-332.

[19] Cantorna, M.T., Snyder, L., Lin, Y.D. and Yang, L. (2015) Vitamin D and 1,25(OH) $)_{2}$ Regulation of T Cells. Nutrients, 7, 3011-3021. https://doi.org/10.3390/nu7043011

[20] Hansen, K.E. (2009) Osteoimmunology: Prevalence of Hypovitaminosis D and Relationship to Fracture. Nature Reviews Rheumatology, 5, 417-418. https://doi.org/10.1038/nrrheum.2009.143

[21] Takayanagi, H. (2007) Interaction between the Immune System and Bone Metabolism: An Emerging Field of Osteoimmunology. The Proceedings of the Japan Acade$m y, 83,136-143$. https://doi.org/10.2183/pjab.83.136

[22] Satué, M., Petzold, C., Córdoba, A., Ramis, J.M. and Monjo, M. (2013) UV Photoactivation of 7-Dehydrocholesterol on Titanium Implants Enhances Osteoblast Differentiation and Decreases Rankl Gene Expression. Acta Biomaterialia, 9, 5759-5770. https://doi.org/10.1016/j.actbio.2012.11.021

[23] Naito, Y., Jimbo, R., Bryington, M., Vandewegh, S., Chrcanovic, B., Tovar, N., Ichikawa, T., Coelho, P. and Wennerberg, A. (2014) The Influence of 1a.25-Dihydroxyvitamin D3 Coating on Implant Osseointegration in the Rabbit Tibia. Journal of Oral \& Maxillofacial Research, 5, e3. https://doi.org/10.5037/jomr.2014.5303

[24] Dvorak, G., Fügl, A., Watzek, G., Tangl, S., Pokorny, P. and Gruber, R. (2012) Impact of Dietary Vitamin D on Osseointegration in the Ovariectomized Rat. Clinical Oral Implants Research, 23, 1308-1313. https://doi.org/10.1111/j.1600-0501.2011.02346.x

[25] Salomo-Coll, O., Mate-Sanchez de Val, J., Rmirez-Fernandez, M., Hernandez-Alfaro, F., Gargallo-Albiol, J. and Calvo-Guirado, J. (2015) Topical Applications of Vitamin D on Implant Surface for Bone to Implant Contact Enhance: A Pilot Study in Dogs Part 2. Clinical Oral Implants Research, 27, 896-903. https://doi.org/10.1111/clr.12707

[26] Cho, Y.J., Heo, S.J., Koak, J.Y., Kim, S.K., Lee, S.J. and Lee, J.H. (2011) Promotion of Osseointegration of Anodized Titanium Implants with a $1 \alpha, 25$-Dihydroxyvitamin D3 Submicron Particle Coating. International Journal of Oral \& Maxillofacial Implants, 26, 1225-1232.

[27] Zhou, C., Li, Y., Wang, X., Shui, X. and Hu, J. (2012) 1, 25Dihydroxy Vitamin D3 Improves Titanium Implant Osseointegration in Osteoporotic Rats. Oral Surgery, Oral Medicine, Oral Pathology and Oral Radiology, 114, S174-S178. https://doi.org/10.1016/j.oooo.2011.09.030

[28] Wu, Y.Y., Yu, T., Yang, X.Y., Li, F., Ma, L., Yang, Y., Gong, P., et al. (2013) Vitamin D3 and Insulin Combined Treatment Promotes Titanium Implant Osseointegration in Diabetes Mellitus Rats. Bone, 52, 1-8. https://doi.org/10.1016/j.bone.2012.09.005

[29] Liu, W., Zhang, S., Zhao, D., Zou, H., Sun, N., Liang, X., Yuan, Q., et al. (2014) Vi- 
tamin D Supplementation Enhances the Fixation of Titanium Implants in Chronic Kidney Disease Mice. PLoS ONE, 9, e95689.

https://doi.org/10.1371/journal.pone.0095689

[30] Mangano, F., Mortellaro, C., Mangano, N. and Mangano, C. (2016) Is Low Serum Vitamin D Associated with Early Dental Implant Failure? A Retrospective Evaluation on 1625 Implants Placed in 822 Patients. Mediators of Inflammation, 2016, Article ID: 5319718. https://doi.org/10.1155/2016/5319718

[31] Schulze-Späte, U., Dietrich, T., Wu, C., Wang, K., Hasturk, H. and Dibart, S. (2016) Systematic Vitamin D Supplementation and Local Bone Formation after Maxillary Sinus Augmentaiton-A Randomized, Double-Blind, Placebo-Controlled Clinical Investigation. Clinical Oral Implants Research, 27, 701-706.

https://doi.org/10.1111/clr.12641 